\title{
Modification of thermal and rheological behavior of asphalt binder by the addition of an ethylene-methyl acrylate-glycidyl methacrylate terpolymer and polyphosphoric acid
}

\author{
Gerson da Silva Pereira ${ }^{1}$ and Ana Rita Morales ${ }^{1 *}$ \\ ${ }^{1}$ Department of Materials Science and Bioprocess, School of Chemical Engineering, \\ Universidade Estadual de Campinas - UNICAMP, Campinas, SP, Brazil \\ *morales@feq.unicamp.br
}

\begin{abstract}
This study evaluated the modification effects of adding ethylene-methyl acrylate-glycidyl methacrylate terpolymer (EMGMA) in the presence of polyphosphoric acid (PPA) to an asphalt binder graded as 50/70 $(0.1 \mathrm{~mm})$ in the Brazilian penetration grade specification (AC 50/70). The EMGMA terpolymer has been presented as a new alternative to modify asphalt binders properties, as scientific literature is scarce on its usage in this context and also on the role of PPA when used in combination with reactive polymers. The characteristics of the modified binder were analyzed by standard and rheological testing, including Multiple Stress Creep Recovery test (MSCR) and Fourier Transform Infrared Spectroscopy (FTIR) analysis. The MSCR test showed that the modified binder presented lower values of non-recoverable compliances $\left(\mathrm{J}_{\mathrm{nr}}\right)$ and a higher percent recovery, when compared to the conventional binder. This behavior indicates that addition of EMGMA and PPA in asphalt binders could enhance the resistance to rutting of asphalt mixtures. The statistical evaluation showed that EMGMA had greater influence on the studied properties of $\mathrm{J}_{\mathrm{nr}}(0.1 \mathrm{kPa}), \mathrm{MSCR}$ recovery, softening point and elastic recovery at $25^{\circ} \mathrm{C}$ and that the PPA had also significant influence on these properties. FTIR analysis showed that chemical reactions occurred between the asphalt binder and EMGMA, forming a three-dimensional polymeric network, which promotes improved characteristics.
\end{abstract}

Keywords: asphalt binder, modified asphalt binders, MSCR, non-recoverable compliance, ethylene-methyl acrylate-glycidyl methacrylate terpolymer.

\section{Introduction}

Modified asphalt binders have been increasingly used in paving applications as an interesting alternative to deal with shortcoming of the petroleum asphalt cement (PAC). Nowadays, the use of modified asphalt binders is an excellent alternative for more durable flexible pavements, improving some deficiencies and enhancing asphalt concrete properties such as resistance to rutting and cracking and reducing the damage due to fatigue and thermal susceptibility ${ }^{[1]}$.

Several polymeric modifiers may confer beneficial characteristics to asphalt binders, among them can be cited styrene-butadiene block copolymer (SBR), styrene-butadiene-styrene (SBS), styrene-isoprene-styrene (SIS), styrene-ethylene-butadiene-styrene (SEBS), acrylonitrile-butadiene-styrene (ABS), ethylene vinyl acetate $(\mathrm{EVA})^{[2]}$. SBS copolymer is considered the most appropriate material for asphalt modification, despite the addition of it has economic limitations and may have serious technical limitations, as the low resistance to heat and oxidation ${ }^{[1]}$.

Reactive terpolymers have been also used as modifiers of asphalts binders. Their reactivity is due to the presence of functional groups that are able to interact with the carboxyl groups of the asphaltenes. The asphaltenes fraction consists of large micelles with average molecular weight estimated between 800-3500 g/mol, and each micelle has a large number of available carboxyl groups, as shown in Figure 1.
The terpolymers reacts with the asphaltenes and develops a chemical bond network between micelles improving the rheological properties of the asphalt binder. Also, there is the epoxy opening ring that can react with the hydroxyl groups and causes the formation of an ether bond. The same reaction may happen through an amino group, and once the epoxy ring is open, crosslinking between the polymer chains may occur, not necessarily involving asphaltene molecules ${ }^{[3]}$. Examples of reactive polymers are thermoplastic elastomers functionalized with maleic anhydride and ethylene copolymers containing epoxy rings ${ }^{[3]}$. Various studies show the improvement of the characteristics of PAC by adding ethylene-butyl acrylate-glycidyl methacrylate terpolymer (EBGMA $^{[3-6]}$. Studies with EBGMA terpolymer show important aspects to be considered in these systems, for instance, the polymer concentration, the curing time and the curing temperature that can promote a substantial increase in viscosity, which may induce the system to gel $^{[3]}$. According to standard tests of penetration, softening point, rotational viscosity and aging, the modified asphalt binder with EBGMA became more consistent and with less thermal susceptibility compared to the unmodified asphalt binder $^{[4]}$. It was also reported that the addition of $1 \%$ EBGMA terpolymer improved the rheological properties of the binder, providing greater resistance to rutting ${ }^{[5]}$. 
Some studies also related the use of the polyphosphoric acid (PPA) in very low amounts to catalyze the reaction between the terpolymer and the asphalt molecular groups, as this is a slow reaction that requires up to 24 hours to complete the cure ${ }^{[3,7]}$. The addition of PPA in modified asphalts can also decrease the amount of polymer, reducing costs ${ }^{[8,9]}$.

Related to the rheological properties, a system of PAC + EBGMA + PPA showed a very high deformation recovery and a very low non-recoverable compliance $\left(\mathrm{J}_{\mathrm{nr}}\right)$ values, as well presented more resistance when subjected to a sudden increase in stress level ${ }^{[5]}$. In other study the addition of EBGMA terpolymer into the PAC modified its rheological properties, evidenced by an increase in the dynamic viscosity and a change of the Newtonian behavior at different temperatures ${ }^{[6]}$.

Currently, the growing demand for modified asphalt binders has encouraged search for alternative new polymeric

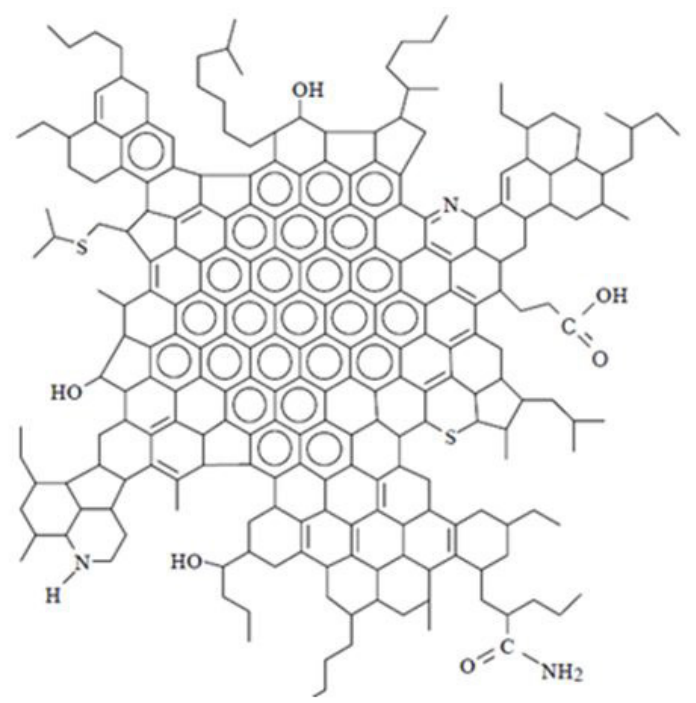

Figure 1. 2-Dimensional model of an asphaltene molecule ${ }^{[10]}$

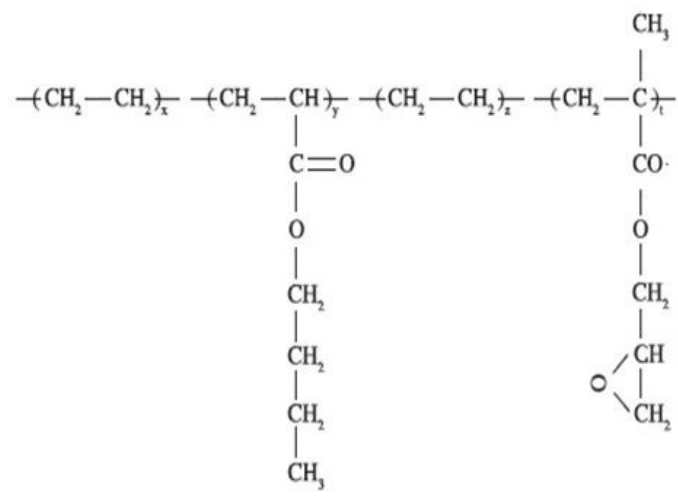

a) materials that meet the performance and economic viability requirements. Within this context, a new ethylene-methyl acrylate-glycidyl methacrylate terpolymer (EMGMA), studied in this paper, was recently introduced to the market, this modifier being the main object of this work. The main difference between the new EMGMA and the most studied terpolymers is the replacement of the butyl acrylate monomer by the methyl acrylate monomer ${ }^{[11]}$. The chemical structure of EBGMA and EMGMA are presented in Figure 2a and b.

In this study, the addition of PPA was also evaluated since several researchers have looked into the use of this acid also as a modifier, either by itself or associated to other modifiers ${ }^{[12-14]}$. As described by many researchers, adding PPA in the PAC increases the content of asphaltenes, because it acts in this fraction as a deflocculant and increases the contact area with the maltenic phase $\mathrm{e}^{[15,16]}$.

Considering that scientific literature on the use of EMGMA terpolymer as asphalt binder modifier is scarce and the PPA function is not clear when used in combination with reactive polymers, this paper presents a laboratorial study of the thermal and rheological behavior for an asphalt binder modified with EMGMA in the presence of PPA in order to understand the polymer and PPA action and the components interactions.

\section{Materials and Methods}

\subsection{Materials}

One PAC from Replan - Petrobras Refinery (Paulinia, São Paulo, Brazil) was used in this study. This unmodified material is graded as 50/70 in the Brazilian penetration grade (AC50/70), indicating a penetration of $50-70(\mathrm{dmm})$, according to ASTM D5-06.

The EMGMA terpolymer was produced by Arkema (Lotader AX8900) and supplied by Quimigel Indústria Comércio Ltd., containing $23.13 \%$ of methyl acrylate and $8.35 \%$ of glycidyl methacrylate, having a glass transition temperature (Tg) of $-2^{\circ} \mathrm{C}$. It was supplied as extruded granules.

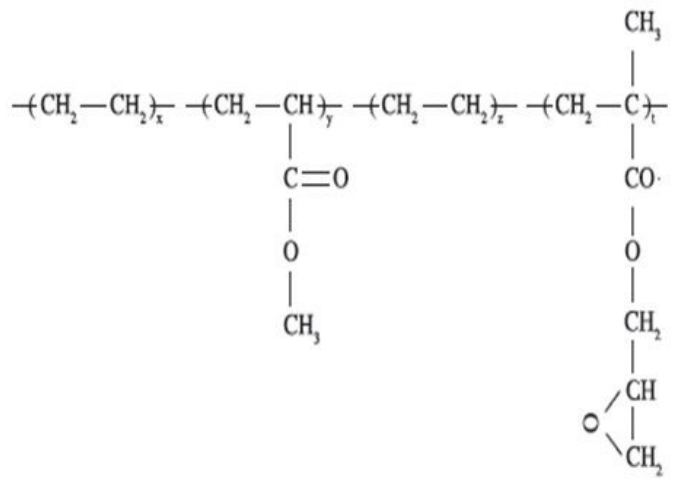

b)

Figure 2. Molecular structure of (a) ethylene-butyl acrylate-glycidyl methacrylate terpolymer and (b) ethylene-methyl acrylate-glycidyl methacrylate terpolymer (adapted from Brito et al. ${ }^{[1]}$ ). 
Polyphosphoric Acid (PPA) is an inorganic oligomer obtained by the condensation of the monophosphoric acid or by the hydration of phosphorus pentoxide $\left(\mathrm{P}_{2} \mathrm{O}_{5}\right)$. The PPA is typically a mixture of orthophosphoric acid with pyrophosphoric acid and triphosphoric acid and does not contain free water. It is produced and marketed based on its relative level of $\mathrm{H}_{3} \mathrm{PO}_{4}$ (phosphoric acid) or $\mathrm{P}_{2} \mathrm{O}_{5}$ (phosphorus pentoxide) in its content ${ }^{[16]}$. In this study was used the PPA at the concentration of $84 \%$ of $\mathrm{P}_{2} \mathrm{O}_{5}$, proportional to $116 \%$ of $\mathrm{H}_{3} \mathrm{PO}_{4}$, supplied by the company Prana Petroquímica Ltda.

\subsection{Preparation of modified asphalt binder samples}

The unmodified PAC was preheated at a temperature of $175^{\circ} \mathrm{C}$ using an electric hot plate. Next, the EMGMA polymer was added to the PAC at the rate of $10 \mathrm{~g} / \mathrm{min}$. An IKA stirrer (model RW20) with a propeller type R 1342 with four blades, was used to promote mixing at a speed of $1750 \mathrm{rpm}$. The stirring was done for $30 \mathrm{~min}$, until the complete dispersion of the polymer, then, the PPA was added, remaining under agitation for additional $90 \mathrm{~min}$.

\subsection{Experimental design}

It was used a factorial experimental design of $2^{2}$, as shown in Table 1, according to the methodology described by Neto et al. ${ }^{[17]}$.

The statistical analysis of the data was performed using the software Statistica 10.0, with a confidence level of $95 \%$. The factorial analysis was used to assess the effects and interactions of the variables in the traditional binder properties of softening point and elastic recovery at $25^{\circ} \mathrm{C}$, and also in the non-recoverable compliance $\left(\mathrm{J}_{\mathrm{nr}}\right)$ and in the percent of recovery, obtained at Multiple Stress Creep and Recovery (MSCR) test.

The properties evaluated by the conventional binder test were: penetration at $25^{\circ} \mathrm{C}\left(\mathrm{ASTM} \mathrm{D} 5-06^{[18]}\right)$, ring-and-ball softening point (ASTM D36-06 ${ }^{[19]}$ ) and elastic recovery by ductilometer - (ASTM D6084-13 ${ }^{[20]}$. The rotational viscosity was measured using a Brookfield Viscometer RVDV-I Prime model with spindle No. 20, according to ASTM D4402-06 ${ }^{[21]}$, at temperatures of $135^{\circ} \mathrm{C}, 155^{\circ} \mathrm{C}$ and $177^{\circ}$ and rotational speeds of $20 \mathrm{rpm}, 50 \mathrm{rpm}$ and $100 \mathrm{rpm}$, respectively. The rheological tests were performed using a dynamic shear rheometer (DSR) from TA Instruments (DHR-1 model), with a parallel plate geometry of $25 \mathrm{~mm}$ diameter and deformation amplitude of $12 \%$, controlled automatically by the equipment software. The dissipation modulus, storage modulus and phase angle were also determined on the same DSR equipment, according ASTM D7175-08 standard ${ }^{[22]}$.

The DSR is used to measure asphalt properties at high and intermediate temperatures. High values of complex shear stiffness modulus $\left(\mathrm{G}^{*}\right)$ represents high rigidity, while a small phase angle represents a greater elastic response (recoverable). An asphalt binder with these properties provides to an asphalt mixtures better resistance to rutting. Thus, the $\mathrm{G}^{*} / \sin \delta$ parameter was originally adopted using the Superpave ${ }^{[23]}$ methodology to express the resistance of asphalt binders to rutting. After the adoption of $\mathrm{G}^{*} / \sin \delta$ in the Superpave specification, various studies showed that it was not appropriated to evaluate modified asphalt binders ${ }^{[24,25]}$ because of its inability to assess the elastic contribution provided by the addition of polymers to the asphalt binders. Thus, in this study, the recovery percentage and the non-recoverable compliance values $\left(\mathrm{J}_{\mathrm{nr}}\right)$ were determined, in the Multiple Stress Creep Recovery test (MSCR), following the procedure established by ASTM D7405-10 ${ }^{[26]}$. The MSCR test applies an oscillatory regime to characterize permanent deformation of asphalt binders. This test was performed on the DSR equipment using unaged asphalt binder samples. In the MSCR test, a constant stress of $0.1 \mathrm{kPa}$ for 1 second is applied on an asphalt sample of $1 \mathrm{~mm}$ thickness and then the load is removed, allowing the material to relax for 9 seconds. This cycle is repeated 10 times, without time intervals between cycles. After these 10 cycles, the same procedure is repeated using a constant stress of $3.2 \mathrm{kPa}$. The recovery percentage is obtained from the ratio of the recoverable deformation and the total deformation, as shown in Equation 1.

$$
R(\sigma, N)=\frac{\left[\left(E_{C-} E_{0}\right)-\left(E_{R-} E_{0}\right)\right] .100}{E_{C-} E_{0}}
$$

Where $\mathrm{R}(\sigma, \mathrm{N})$ is the percent recovery under stress $\sigma$ $(0.1 \mathrm{kPa}$ or $3.2 \mathrm{kPa})$ and $\mathrm{N}$ is the cycle of the creep and recovery $(1 \leq \mathrm{N} \leq 10)$. Figure 3 shows the deformation values used for the calculations.

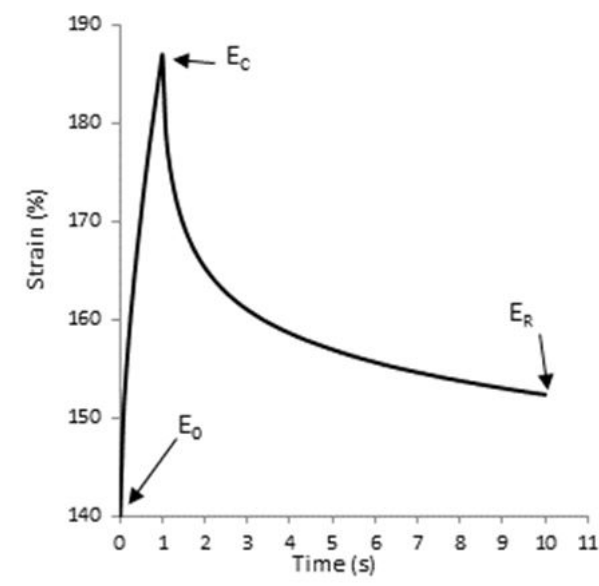

Figure 3. Deformations $E_{0}, E_{C}$ and $E_{R}$ for one creep and recovery cycle of the MSCR test.

Table 1. Experimental design $2^{2}$ for AC 50/70, EMGMA and PPA.

\begin{tabular}{cccc}
\hline Independent variables & \% EMGMA Polymer & \% PPA & Sample nomenclature \\
\hline & 1.0 & 0.05 & $(1 \%$ EMGMA $+0.05 \%$ PPA $)$ \\
Levels & 2.0 & & $(2 \%$ EMGMA $+0.05 \%$ PPA $)$ \\
& 1.0 & 0.30 & $(1 \%$ EMGMA $+0.30 \%$ PPA $)$ \\
& 2.0 & & $(2 \%$ EMGMA $+0.30 \%$ PPA $)$ \\
\hline
\end{tabular}


The non-recoverable compliance is the ratio of the non-recoverable deformation and the stress applied, and is typically expressed as the inverse of the stress unit $\left(\mathrm{Pa}^{-1}\right.$ or $\left.\mathrm{kPa}^{-1}\right)$, according to Equation 2 .

$$
J_{N R}(\sigma, N)=\frac{E_{R-} E_{0}}{\sigma}
$$

Where $J_{n r}(\sigma, N)$ is the non-recoverable compliance relative to the stress $\sigma$ at the creep and recovery cycle $\mathrm{N}$, $(1 \leq \mathrm{N} \leq 10$ and $\sigma=0.1 \mathrm{kPa}$ or $3.2 \mathrm{kPa})$. With all the results of $\mathrm{R}(\sigma, \mathrm{N})$ and $\mathrm{J}_{\mathrm{nr}}(\sigma, \mathrm{N})$ obtained in the 10 creep and recovery cycles, their average results were calculated by means of the simple arithmetic average. Studies have demonstrated that the $\mathrm{J}_{\mathrm{nr}}$ value has good correlations with rutting measurements on asphalt mixtures ${ }^{[27,28]}$.

With the purpose to investigate the chemical reaction that may occur between the asphalt binder and the EMGMA, analysis were performed by Fourier Transform Infrared Spectroscopy (FTIR) on a spectrometer Thermo Scientific Nicolet 670 model, measured in transmittance mode, in the range of $4000-675 \mathrm{~cm}^{-1}$.

\section{Results and Discussion}

Table 2 shows the results for unmodified and modified asphalt binder samples produced in accordance to the experimental design. The results indicated that binder with a higher PPA content had lower penetration values. Significant increase of the softening point was observed for all modified asphalt binder samples, increasing from $49^{\circ} \mathrm{C}$ to $76^{\circ} \mathrm{C}$ for the sample with $2 \%$ EMGMA $+0.30 \%$ PPA, which shows a lower temperature sensitivity of the asphalt binder. In the elastic recovery test performed at $25^{\circ} \mathrm{C}$, it was noted that the modified binders have up to 6 times elastic recovery, when compared to the unmodified binder. The increase of the elastic recovery and the softening point values even with low EMGMA and PPA levels indicates that the terpolymer promotes the formation of a polymeric network, capable to provide an improvement in the elasticity of the PAC, as described also by Polacco et al. ${ }^{[3]}$ using the terpolymer EBGMA.

Table 3 and Figure 4 present the results of rotational viscosity at high temperatures. It is noted that the addition of EMGMA increased the rotational viscosity of the asphalt binder. Adding higher amounts of PPA to the modified binders for the same EMGMA content, the rotational viscosity also increased, which may be associated to the crosslinking process. This behavior was also observed by other researchers when EBGMA was used ${ }^{[3,6]}$.

As observed from the softening point and the elastic recovery results, a polymeric network in the asphalt matrix may be developed, which also promotes an increase of the rotational viscosity, hindering the molecules flow.

The rotational viscosity is important to measure the consistency properties of asphalt binder, which are used as a guide for processing and storing temperatures. Asphalt binders excessively viscous can be inappropriate to be used in asphalt mixtures.

In Brazil, a maximum rotational viscosity is specified for modified asphalt binders at each temperature, as shown in Table $3^{[29]}$. Therefore, as shown by the experimental data in Figure 4, only the modified asphalt binder with $2 \%$ EMGMA $+0.30 \%$ PPA exceeded the $3000 \mathrm{cP}$ viscosity limit, indicating the possibility of operational problems.

The data obtained at the laboratory tests were analyzed using the Statistica software 10.0, at 95\% confidence level and it was possible to evaluate the effects and interactions of the variables in the responses. This method is useful to analyze the results in a statistical base, pointing out the factors that are statistically significant. Figures 5 and 6 illustrates the effects and interactions of each factor (EMGMA \% and PPA \%) regarding the softening point and elastic recovery.

Figures 5 and 6 show that both, the EMGMA concentration as the PPA concentration, influence in the evaluated properties, with a statistically significance $(\mathrm{p}<0.05)$. The concentration of EMGMA was the most influential factor, because of its higher value in the softening point and elastic recovery

Table 2. Results of conventional tests of the AC 50/70 and the modified asphalt binder samples.

\begin{tabular}{cccc}
\hline Sample & Penetration $(\mathbf{d m m})$ & Softening point $\left({ }^{\circ} \mathbf{C}\right)$ & Elastic recovery $(\%)$ \\
\hline AC 50/70 base binder & $55+/-1$ & $49.0+/-0.8$ & $9.0+/-0.3$ \\
$(1 \%$ EMGMA + 0.05\% PPA $)$ & $53+/-1$ & $55.0+/-0.6$ & $71.0+/-0.8$ \\
$(1 \%$ EMGMA + 0.30\% PPA $)$ & $48+/-1$ & $62.0+/-0.3$ & $77.0+/-0.8$ \\
$(2 \%$ EMGMA + $0.05 \%$ PPA $)$ & $58+/-1$ & $66.0+/-0.5$ & $83.0+/-1.0$ \\
$(2 \%$ EMGMA + $0.30 \%$ PPA $)$ & $48+/-1$ & $77.0+/-0.8$ & $92.0+/-0.8$ \\
\hline
\end{tabular}

Table 3. Rotational viscosity results and the maximum limits according to Brazilian specification.

\begin{tabular}{|c|c|c|c|}
\hline \multirow{2}{*}{ Sample } & \multicolumn{3}{|c|}{ Rotational viscosity (cP) } \\
\hline & $135^{\circ} \mathrm{C}$ & $150^{\circ} \mathrm{C}$ & $177^{\circ} \mathrm{C}$ \\
\hline Spindle rotation speed & $20 \mathrm{rpm}$ & $50 \mathrm{rpm}$ & $100 \mathrm{rpm}$ \\
\hline Maximum limit ${ }^{[29]}$ & 3000 & 2000 & 1000 \\
\hline AC $50 / 70$ base binder & 345 & 158 & 63 \\
\hline$(1 \%$ EMGMA $+0.05 \%$ PPA $)$ & 625 & 304 & 110 \\
\hline$(1 \%$ EMGMA + $0.30 \%$ PPA $)$ & 937 & 388 & 145 \\
\hline$(2 \%$ EMGMA $+0.05 \%$ PPA $)$ & 1155 & 450 & 140 \\
\hline$(2 \%$ EMGMA $+0.30 \%$ PPA $)$ & 3840 & 1422 & 343 \\
\hline
\end{tabular}




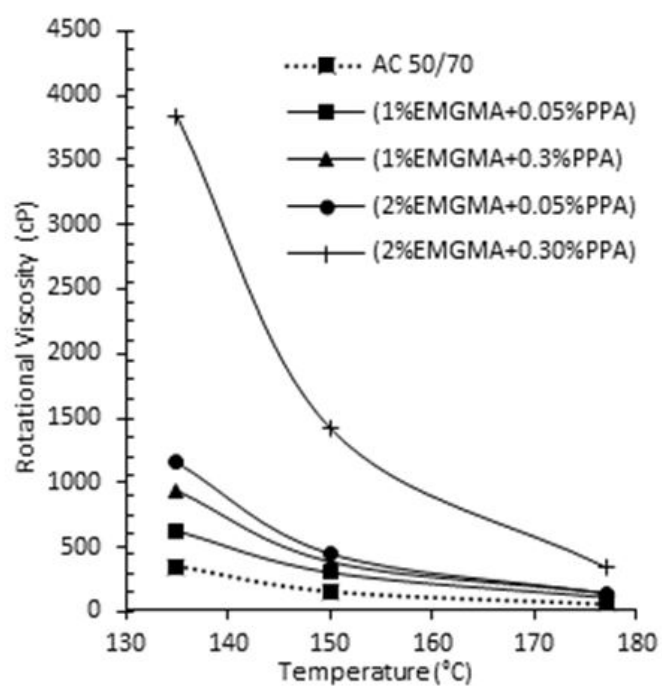

Figure 4. Rotational viscosities for the asphalt binder AC 50/70 and modified samples at temperatures of $135^{\circ} \mathrm{C}, 150^{\circ} \mathrm{C}$ and $177^{\circ} \mathrm{C}$. tests. Besides, there is a significant interaction between the factors in both responses, showing more pronounced in the softening point test. The evaluation of the response surface (Figure $5 \mathrm{~b}$ and $6 \mathrm{~b}$ ) confirms that the concentration of EMGMA is the factor that most contributes to the increase of softening point and elastic recovery, but it is observed that the concentration of PPA also has strong influence on elastic recovery response. This suggests that PPA acts as a co-modifier of the PAC + EMGMA system, providing improved characteristics to the asphalt binder.

Conventional tests employed in the characterization of asphalt binder do not allow the determination of fundamental properties related to paved runway performance due to empiricism involved and practical complications related to the results interpretation ${ }^{[30]}$. To address this deficiency new tests based on rheological properties related to the performance of the asphalt mixture were established by the Superpave specification ${ }^{[25,26]}$. Thus, MSCR test was used to better assess the samples performance at performance temperatures of flexible pavements. The results of MSCR are shown in Figure 7 and it is noted that when EMGMA

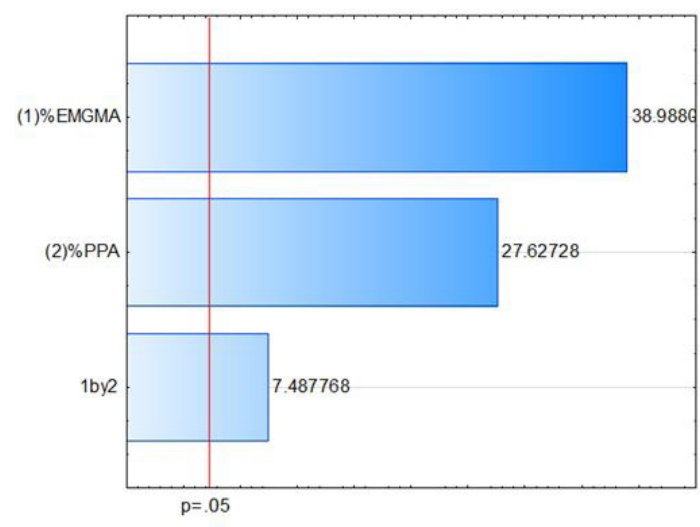

a)

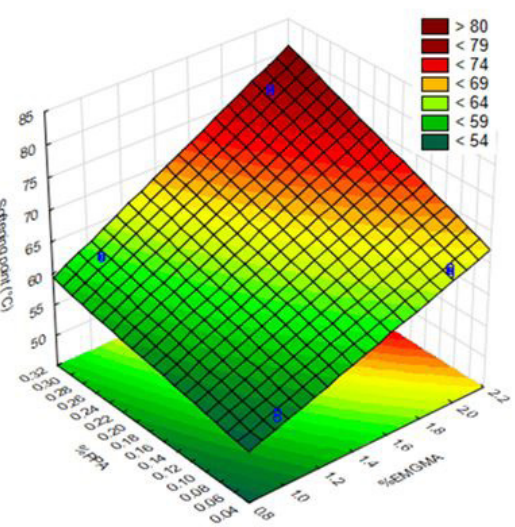

b)

Figure 5. Softening point (a) Pareto chart and (b) response surface.

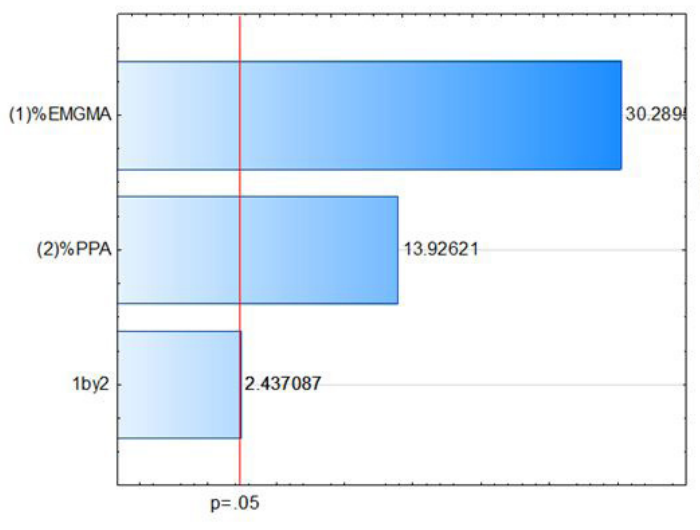

a)

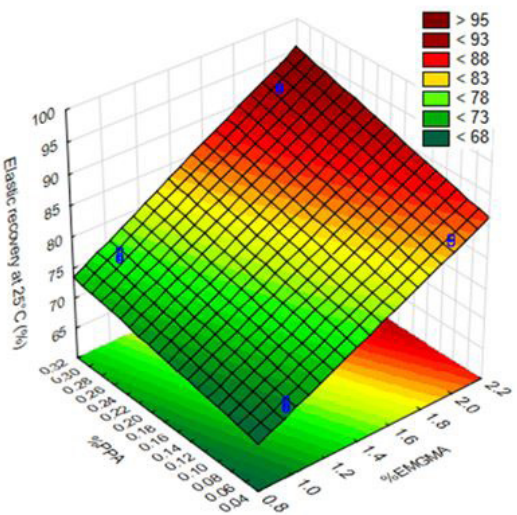

b)

Figure 6. Elastic recovery at $25^{\circ} \mathrm{C}$ (a) Pareto chart and (b) response surface. 


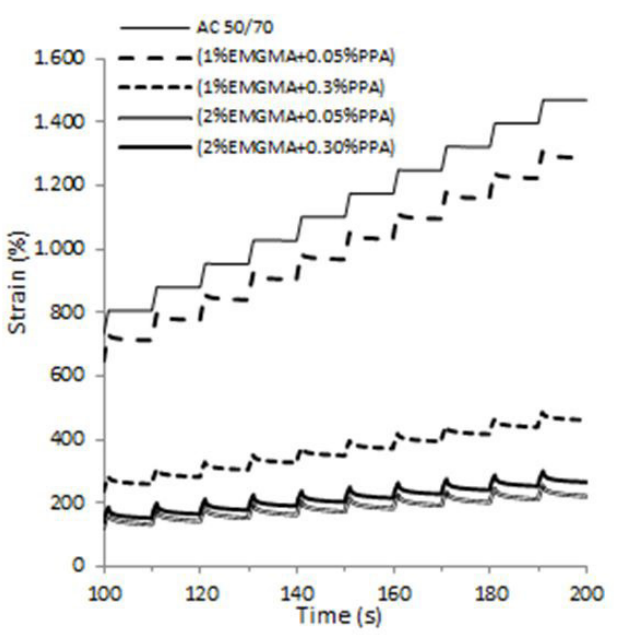

a)

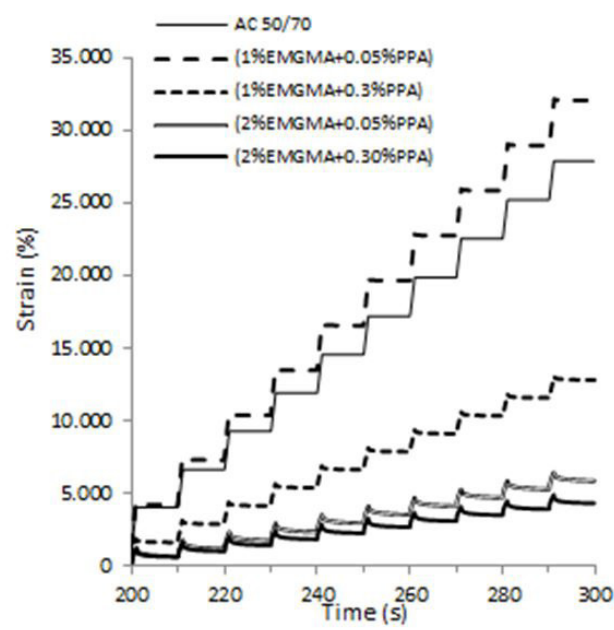

b)

Figure 7. MSCR results for the applied stress of (a) $0.1 \mathrm{kPa}$ and (b) $3.2 \mathrm{kPa}$.

content and PPA content are increased, the deformation decreases and the deformation recovery enhances.

The overall behavior of the samples, observed at MSCR test, was similar at both applied stresses levels $(3.2 \mathrm{kPa}$ and $0.1 \mathrm{kPa})$. However, as expected, higher deformation was obtained at the stress of $3.2 \mathrm{kPa}$. Only the sample with $1 \%$ EMGMA $+0.05 \%$ PPA showed a greater deformation compared to the AC50/70.

In Figure 8 are shown the $0.1 \mathrm{kPa}$ and $3.2 \mathrm{kPa}$ recovery results obtained by MSCR test and it can seen an increase in the deformation recovery because of the addition of EMGMA polymer. Samples with 1\% EMGMA content exhibit significant recovery enhancement with increase in PPA addition. Samples with 2\% EMGMA show the same behavior.

The effects and interactions of the MSCR recovery percentage at the stress of $0.1 \mathrm{kPa}$ are illustrated in Figure 9. It is noted that the EMGMA concentration has a high contribution in this property. Additionally, the lower PPA concentration significantly affects the response, but a higher percentage of PPA did not contribute to the increase of the MSCR recovery.

The non-recoverable compliance values (Jnr) at the stresses of $0.1 \mathrm{kPa}$ and $3.2 \mathrm{kPa}$ are shown in Figure 10 . Again, higher concentrations of EMGMA and PPA decrease the non-recoverable compliance values, except sample with $1 \%$ EMGMA and $0.05 \%$ of PPA. This behavior confirms the better performance of the modified binder, obtaining a EMGMA + PPA system that could contribute towards better rutting resistance of asphalt mixtures.

The statistical analysis of the effects and interaction of the variables on non-recoverable compliance (Jnr) response at the stress of $0.1 \mathrm{kPa}$ stress is shown in Figure $11 \mathrm{a}$ and $\mathrm{b}$. Both variables (PPA\% and EMGMA\%) influence this response and the EMGMA concentration has a higher

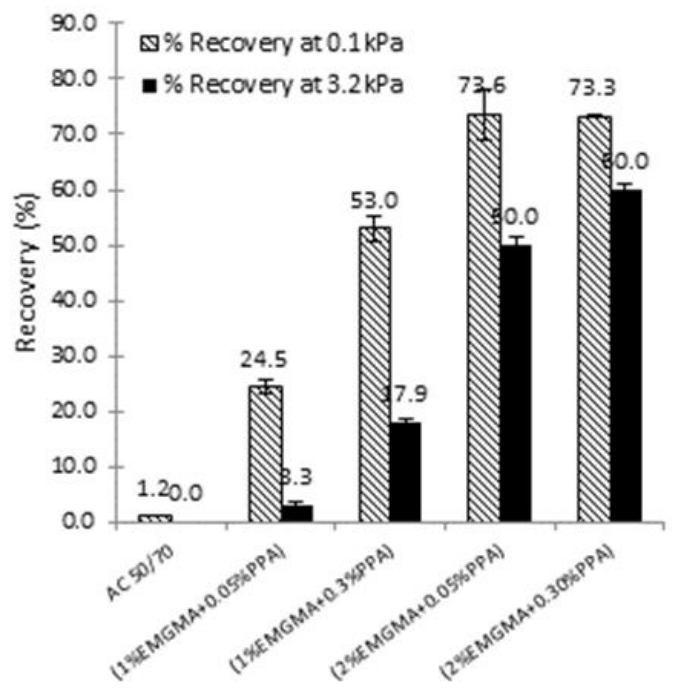

Figure 8. MSCR recovery percentage at stresses of $0.1 \mathrm{kPa}$ and $3.2 \mathrm{kPa}$.

significance. The interaction between the two variables was more significant than the PPA concentration.

The MSCR test results obtained in this study using EMGMA are similar to those observed with EBGMA terpolymer, indicating that the mechanism of action in both cases are similar ${ }^{[5]}$. The improvement of the elastic characteristics with minimum percentage of EMGMA and PPA can only be explained by the formation of a three-dimensional polymer network formed by the bonding of epoxy groups EMGMA with asphaltene molecules ${ }^{[3]}$.

The rheological properties of the samples were also studied in the linear viscoelastic region, defined as the strain interval where the complex modulus $\left(\mathrm{G}^{*}\right)$ does 


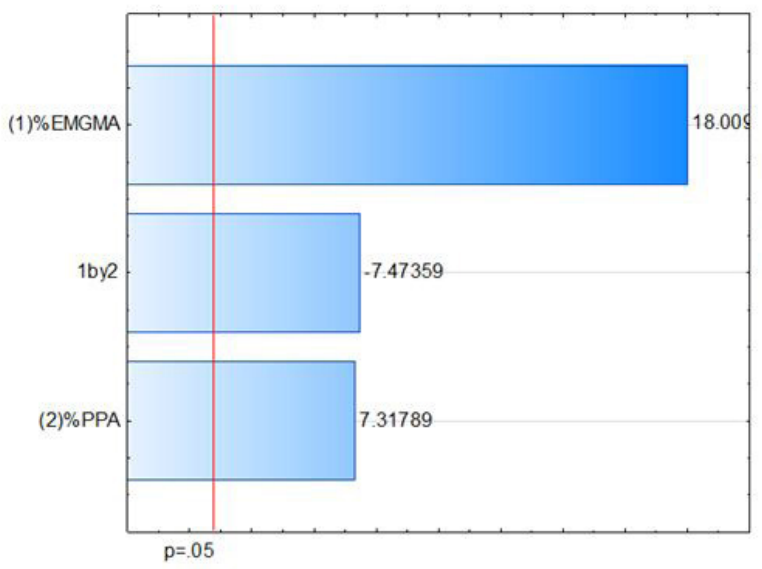

a)

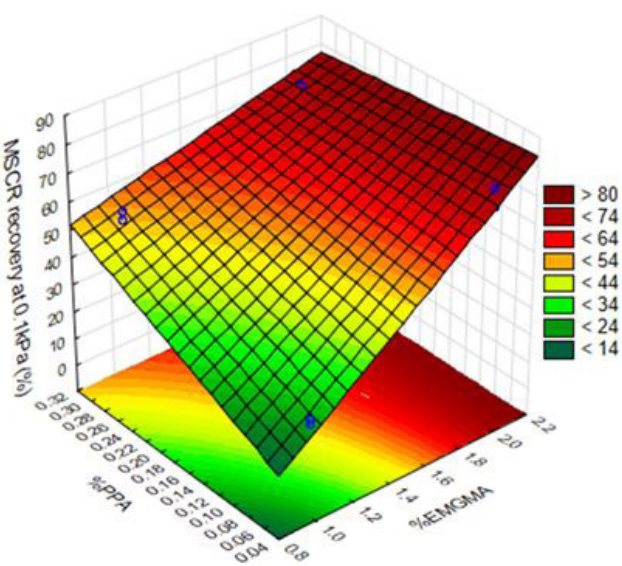

b)

Figure 9. MSCR recovery at the stress of $0.1 \mathrm{kPa}$ (a) Pareto chart and (b) response surface.

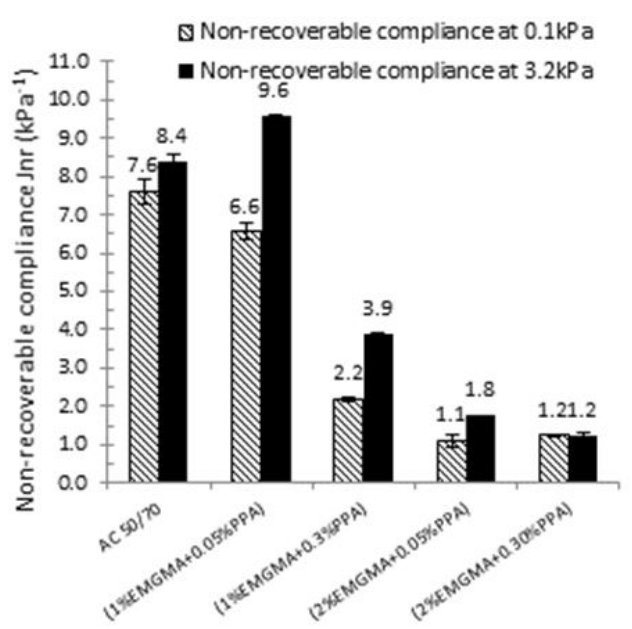

Figure 10. Average of non-recoverable compliances (Jnr) at the stresses of $0.1 \mathrm{kPa}$ and $3.2 \mathrm{kPa}$.

not vary with the applied shear stress, considering an accuracy of $5 \%$ for constant temperature and frequency ${ }^{[24]}$. Results of the complex modulus $\left(\mathrm{G}^{*}\right)$ test were used to construct curves to better assess the modified samples. Figure 12 shows the results, indicating that the modification process significantly extended the linear viscoelastic region for the samples (2\% EMGMA + $0.05 \%$ PPA) and $(2 \%$ EMGMA $+0.30 \%$ PPA $)$. It is also observed a total overall linearity for the complex modulus to shear stress values between 90 and $150 \mathrm{~Pa}$, that corresponds to the shear stress specified for the dynamic-mechanical tests for an asphalt binder without aging.

Figure 13 shows the viscoelastic behavior of modified asphalt binder, represented by the storage modulus $\left(\mathrm{G}^{\prime}\right)$ and the loss modulus (G") as function of the temperature. As the EMGMA polymer and PPA percentage increase, the storage modulus ( $G^{\prime}$ ) also increases in all modified asphalt binder samples, indicating an improvement in the elastic behavior of the asphalt. The viscous dissipation, represented by loss modulus (G”) values indicate that, at relatively low temperatures $\left(52^{\circ} \mathrm{C}\right)$, asphalts behave in a similar manner regarding the viscous component; however, with the increase of the temperature a gap is noted between unmodified asphalt binder and the modified samples. The viscoelastic behavior of the binder is also evaluated using the phase angle $(\delta)$. At intermediate temperatures (normal conditions in asphalt mixtures), the asphalt binder has a viscoelastic behavior, and depending on the temperature and frequency, the peak response of asphalt binders may occur at any point for $\delta$ between 0 and $90^{\circ}$. This delay $(\delta)$ is a fundamental property to describe the viscoelastic behavior of asphalt binders.

The higher the phase angle $(\delta)$ the higher the predominance of the viscous component. Figure 14 presents the $\delta$ values of the samples studied. The unmodified asphalt binder had $\delta$ of $89^{\circ}$ at $82^{\circ} \mathrm{C}$ showing a predominance of the viscous component. The sample ( $2 \%$ EMGMA $+0.30 \%$ PPA) had the lowest $\delta$ value, $55^{\circ}$ at the same temperature, indicating a significant increase in the elastic properties of the modified asphalt.

Figure 15a shows the FTIR spectrum of the unmodified asphalt binder, EMGMA and the sample 2\%EMGMA $+0.3 \% \mathrm{PPA}$ recorded in the range $2000-600 \mathrm{~cm}^{-1}$. The FTIR spectrum corresponding to EMGMA terpolymer shows a remarkable band at $1736 \mathrm{~cm}^{-1}$, which is assigned to the carbonyl stretching $(\mathrm{C}=\mathrm{O})$ of glycidyl methacrylate $(\mathrm{GMA})^{[31,32]}$. There are two bands of stretching vibration for ester compound: one is $v_{\text {as }(\mathrm{C}-\mathrm{O}-\mathrm{C})}$ at $1195 \mathrm{~cm}^{-1}$, the other is $v_{\mathrm{s}(\mathrm{C}-\mathrm{O}-\mathrm{C})}$ at $1164 \mathrm{~cm}^{-1}$. There is also a weak shoulder around $910 \mathrm{~cm}^{-1}$ characteristic of the epoxy group ${ }^{[11,31,32]}$.

Comparing the spectrum of unmodified asphalt binder and the modified one, the bands show few differences. Therefore, it is not possible to identify any product of the reaction between the unmodified asphalt binder and EMGMA.

Figure $15 \mathrm{~b}$ presents a zoom that shows that the band characteristic of the epoxy group at $910 \mathrm{~cm}^{-1}$ disappears in the modified asphalt binder. This indicates that the epoxy 


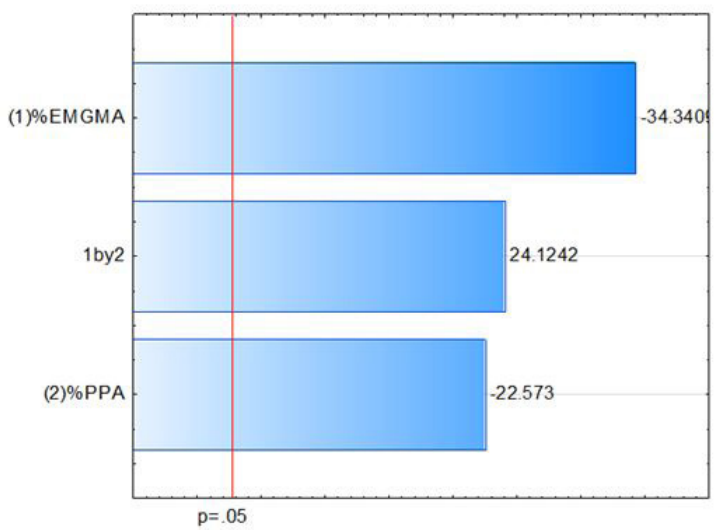

a)

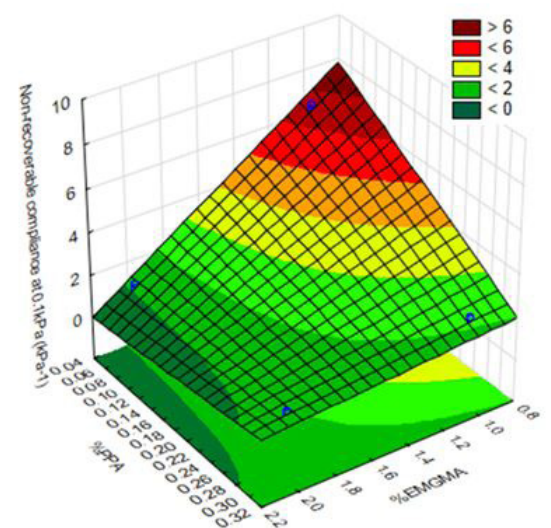

b)

Figure 11. Non-recoverable compliance $\left(\mathrm{J}_{\mathrm{nr}}\right)$ at the stress of $0.1 \mathrm{kPa}$ (a) Pareto chart and (b) response surface.

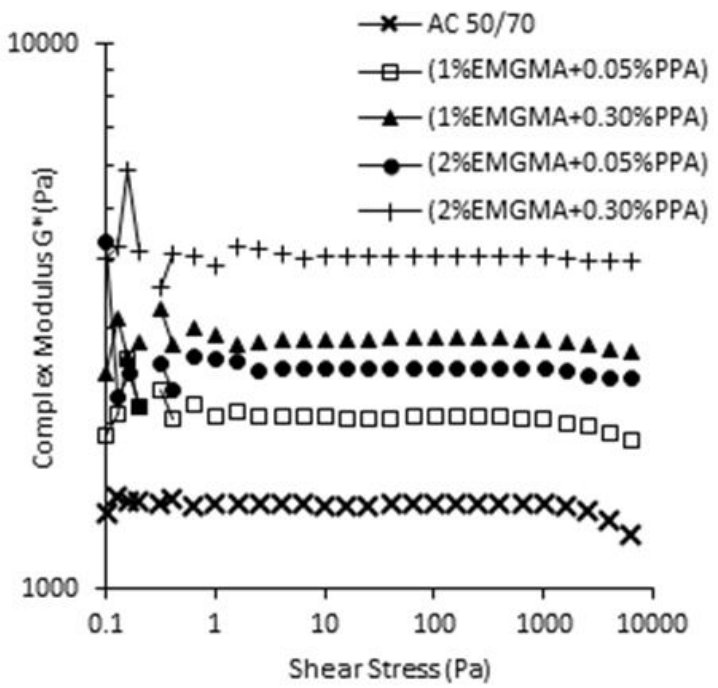

Figure 12. Modulus complex $\mathrm{G}^{*}$ as function of the shear stress for the samples tested at $64^{\circ} \mathrm{C}$.

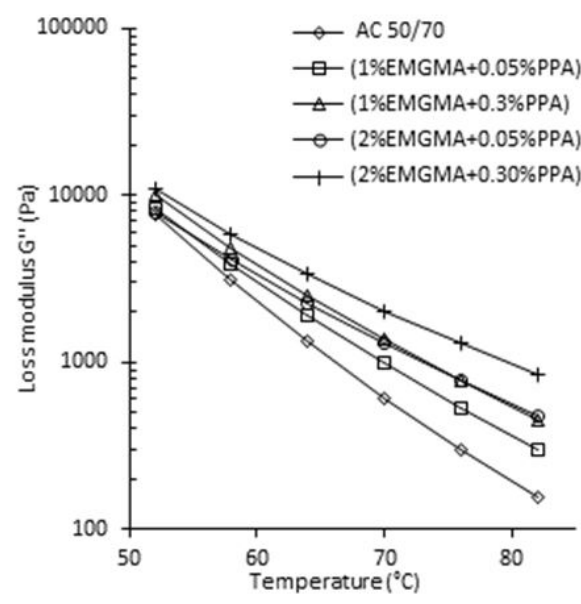

a)

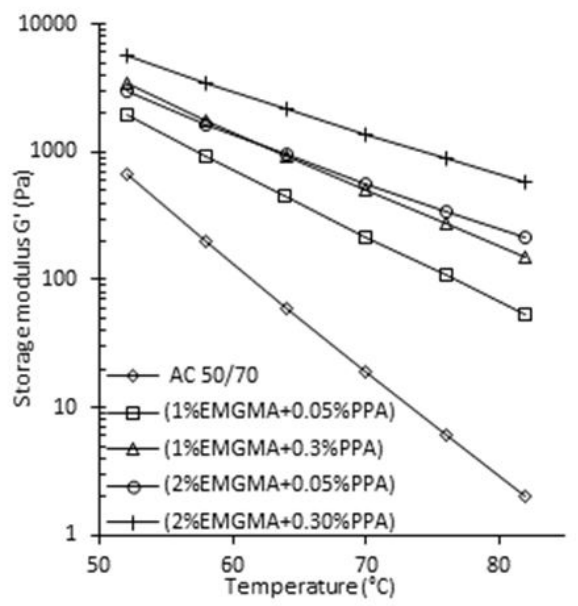

b)

Figure 13. (a) Loss modulus (G') and (b) storage modulus (G') as function of the temperature. 


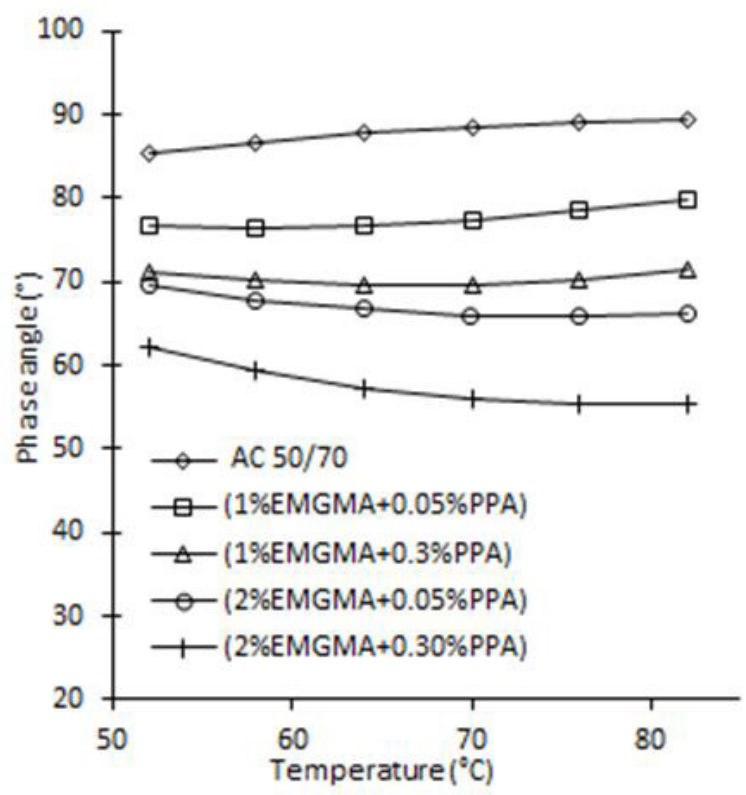

Figure 14. Phase angle $(\delta)$ as function of the temperature.

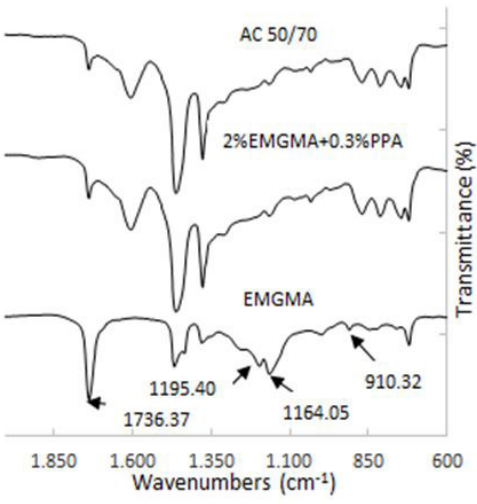

a)

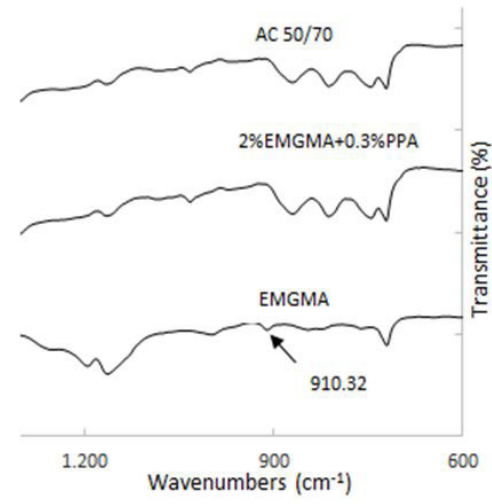

b)

Figure 15. (a) FTIR spectrum of unmodified asphalt binder, pure EMGMA and the sample $2 \% \mathrm{EMGMA}+0.3 \% \mathrm{PPA}$; (b) zoom for the epoxy groups.

rings of the EMGMA opened and reacted with the carboxyl groups in asphaltenes forming ester groups that are not differentiated from existing in the original material. As the epoxy groups EMGMA have a greater affinity reaction with the hydroxyl and carboxyl groups, and is more reactive with the carboxyl groups than with hydroxyl groups ${ }^{[11]}$, the interaction between the terpolymer EMGMA and the PAC probably due the carboxylic groups that exist in abundance in the asphaltene fraction ${ }^{[3,10]}$. Moreover, many changes occur in the PAC because of the modification action of PPA that can be explained by the increase in the content of asphaltenes, as PPA acts as a deflocculant of this fraction, leading to an increase of the contact area of asphaltenes with maltenic phase ${ }^{[15,16]}$. Furthermore, at the beginning of the modification process, the dispersion of EMGMA and the reaction with the carboxylic groups in the asphaltene fraction happens, but this reaction is slow ${ }^{[3,7]}$. With the addition of the PPA the deflocculation of asphaltene micelles occurs, which leverages the effect of EMGMA. Thus, a three-dimensional network which connects the asphaltene micelles is formed, as well as cross-reactivity with the polymer chain itself, contributing to the gain of the elastic properties of the asphalt binder.

\section{Conclusion}

The addition of EMGMA terpolymer and the PPA into the asphalt binder AC 50/70 produced modified asphalt binders with improved elastic properties, as evidenced by the softening point tests and elastic recovery at $25^{\circ} \mathrm{C}$. 
The viscoelastic behavior showed lower phase angle values and higher storage modulus values.

The Multiple Stress Creep Recovery (MSCR) tests showed lower deformation and higher recovery stress values in the modified asphalt binders, besides, the results of non-recoverable compliances $\left(\mathrm{J}_{\mathrm{nn}}\right)$ for applied stresses of $0.1 \mathrm{kPa}$ and $3.2 \mathrm{kPa}$ had a considerable decrease when EMGMA and PPA concentrations were increased. This fact is indicating that the modified asphalt binder may have a greater elastic response during the service conditions, contributing for a longer lifetime of the asphalt mixture in flexible pavements and a reduction in the susceptibility to rutting at longer loading-unloading times.

The statistical evaluation results give support to conclude that the EMGMA has greater influence on the non-recoverable compliance $\left(\mathrm{J}_{\mathrm{nr}}\right)$ at $0.1 \mathrm{kPa}$, softening point and elastic recovery at $25^{\circ} \mathrm{C}$. The PPA has also a significant influence on properties, meaning that it acts not only as a catalyst of the reaction between the asphalt components and the EMGMA terpolymer. There was also a significant interaction between the factors EMGMA $\%$ and PPA $\%$.

FTIR spectrum showed that epoxy functional group of EMGMA disappear in the modified asphalt binder. The improvement of the elastic characteristics with very low amount of EMGMA and PPA can only be explained by the development of a three-dimensional network formed by the reaction of epoxy groups EMGMA with the functional groups of the asphaltene molecules, while the PPA acts as a co-modifier.

The results presented agree to those observed with EBGMA terpolymer, indicating that the mechanisms of action in both cases are similar.

\section{References}

1. Yildirim, Y. (2005). Polymer modified asphalt binders. Construction \& Building Materials, 21(1), 66-72. http://dx.doi. org/10.1016/j.conbuildmat.2005.07.007.

2. Bernucci, L. B., Ceratti, J. A. P., Soares, J. B., \& Motta, L. M. G. (2008). Pavimentação Asfáltica: formação básica para engenheiros. Rio de Janeiro: Abeda.

3. Polacco, G., Stastna, J., Biondi, D., Antonelli, F., Vlachovicova, Z., \& Zanzotto, L. (2004). Rheology of asphalts modified with glycidylmethacrylate functionalizes polymers. Journal of Colloid and Interface Science, 280(2), 366-373. PMid:15533409. http:// dx.doi.org/10.1016/j.jcis.2004.08.043.

4. Topal, A. (2009). Evaluation of the properties and microstructure of plastomeric polymer modified bitumen. Fuel Processing Technology, 91(1), 45-51. http://dx.doi.org/10.1016/j. fuproc.2009.08.007.

5. Domingos, M. D. I., \& Faxina, A. L. (2015). Rheological analysis of asphalt binders modified with Elvaloy ${ }^{\circledR}$ terpolymer and polyphosphoric acid on the multiple stress creep and recovery test. Materials and Structures, 48(5), 1405-1416. http://dx.doi.org/10.1617/s11527-013-0242-y.

6. Tomé, L. G. A., Soares, J. B., \& Lima, C. S. (2004). Estudo do cimento asfáltico de petróleo modificado pelo terpolímero de etilieno-butilacrilato-glicidilmetacrilato. In Anais do $3^{\circ}$ Congresso Brasileiro de P\&D em Petróleo e Gás (p. 1-6). Rio de Janeiro: Instituto Brasileiro de Petróleo e Gás - IBP. Retrived in 2015, April 3, from http://www.portalabpg.org.br/ PDPetro/3/trabalhos/IBP0499_05.pdf
7. DuPont. DuPont ${ }^{\mathrm{T} M}$ Elvaloy ${ }^{\circledR}$ Ret Lab Screening Guide: Technical Bulletin RET 1.1: Suggested Guidelines for Initial Screening of Elvaloy ${ }^{\circledR}$ RET in Asphalt for Paving Applications. Delaware: DuPont, 2015. Retrived in 2015, March 28, from http://www. dupont.com/content/dam/dupont/products-and-services/ additives-and-modifiers/additives-and-modifiers-landing/ documents/ret-asphalt-for_paving-lab-screening_guide.pdf

8. Van der Werff, J. C., \& Nguyen, S. M. (1996). US Patent No 5.519.073A. Washington: U.S. Patent and Trademark Office.

9. Kodrat, I., Sohn, D., \& Hesp, S. (2007). Comparison of polyphosphoric acid-modified binders with straight and polymer-modified materials. Transportation Research Record, 1998, 47-55. http://dx.doi.org/10.3141/1998-06.

10. Murgich, J., Rodriguez, J., \& Aray, Y. (1996). Molecular recognition and molecular mechanics of micelles of some model asphaltenes and resins. Energy \& Fuels, 10(1), 68-76. http://dx.doi.org/10.1021/ef950112p.

11. Brito, G. F., Agrawal, P., Araújo, E. M., \& Melo, T. J. A. (2012). Tenacificação do Poli(Ácido Lático) pela Adição do Terpolímero (Etileno/Acrilato de Metila/Metacrilato de Glicidila). Polímeros: Ciência e Tecnologia, 22(2), 164-169. http://dx.doi.org/10.1590/S0104-14282012005000025.

12. Pamplona, T. F., Nuñez, J. Y. M., \& Faxina, A. L. (2014). Desenvolvimentos recentes em ensaios de fadiga em ligantes asfálticos. Revista Transportes, 22(3), 12-25. http://dx.doi. org/10.14295/transportes.v22i3.682.

13. Pamplona, T. F., Sobreiro, F. P., Faxina, A. L., \& Fabbri, G. T. P. (2012). Propriedades reológicas sob altas temperaturas de ligantes asfálticos de diferentes fontes modificados com ácido polifosfórico. Revista Transportes, 20(4), 5-11. http:// dx.doi.org/10.4237/transportes.v20i4.612.

14. Orange, G., Dupuis, D., Martin, J. V., Farcas, F., Such, C., \& Marcant, B. (2004). Chemical modification of bitumen through polyphosphoric acid: properties- microstructure relationship. In Proceedings of the 3rd Eurasphalt \& Eurobitume Congress (p. 733-745). The Netherlands: Foundation Eurasphalt. Retrived in 2015, April 12, from http://worldcat.org/isbn/9080288446

15. Baumgardner, G. L., Masson, J. F., Hardee, J. R., Menapace, A. M., \& Williams, A. G. (2005). Polyphosphoric acid modified asphalt: proposed mechanisms. Journal of the Association of Asphalt Paving Technologists, 74, 283-306.

16. Masson, J. F. (2008). Brief review of the Chemistry of Polyphosphoric Acid (PPA) and Bitumen. Energy \& Fuels, 22(4), 2637-2640. http://dx.doi.org/10.1021/ef800120x.

17. Neto, B., Scarminio, I. S., \& Bruns, R. E. (2007). Como fazer experimentos: pesquisa e desenvolvimento na ciência e na indústria. Campinas: Editora Unicamp.

18. American Society for Testing and Materials - ASTM. (2006). ASTM D5-06: Standard Test Method for Penetration of Bituminous Materials. West Conshohocken: ASTM.

19. American Society for Testing and Materials - ASTM. (2006). ASTM D36-06: Standard Test Method for Softening Point of Bitumen (Ring-and-Ball Apparatus). West Conshohocken: ASTM.

20. American Society for Testing and Materials - ASTM. (2013). ASTM D6084/D6084M - 13: Standard Test Method for Elastic Recovery of Bituminous Materials by Ductilometer. West Conshohocken: ASTM.

21. American Society for Testing and Materials - ASTM. (2006). ASTM D4402-06: Standard Test Method for Viscosity Determination of Asphalt at Elevated Temperatures Using a Rotational Viscometer. West Conshohocken: ASTM.

22. American Society for Testing and Materials - ASTM. (2008). ASTM D7175-08: Standard test method for determining dynamical shear rheometer (DSR). West Conshohocken: ASTM.

23. Transportation Research Board (2010). Development of the SHRP Binder Specification (Transportation Research Circular 
E-C147). Washington: Transportation Research Board. Retrived in 2015, March 15, from http://onlinepubs.trb.org/onlinepubs/ circulars/ec147.pdf

24. Bouldin, M. G., Dongré, R., \& D’Angelo, J. (2001). Proposed refinement of Superpave high-temperature specification parameter for performance-graded binders. Transportation Research Record, 1766, 40-47. http://dx.doi.org/10.3141/176606.

25. D'Angelo, J. (2015). Multi-stress creep and recovery test method a new specification. Austin: Association of Modified Asphalt Producers - AMAP. Retrived in 2015, March 15, from $\mathrm{http} / /$ amap.ctcandassociates.com/wp/wp-content/uploads/ dangelo-MSCR-2-08E.pdf

26. American Society for Testing and Materials - ASTM. (2010). ASTM D7405-10: Standard Test Method for Multiple Stress Creep and Recovery of Asphalt Binder Using a Dynamic Shear Rheometer. West Conshohocken: ASTM.

27. Hafeez, I., \& Kamal, M. A. (2014). Creep compliance: a parameter to predict rut performance of asphalt binders and mixtures. Arabian Journal for Science and Engineering, 39(8), 5971-5978. http://dx.doi.org/10.1007/s13369-014-1216-2.

28. Adorjányi, K., \& Fuleki, P. (2013). Correlation between permanent deformation-related performance parameters of asphalt concrete mixes and binders. Central European Journal of Engineering, 3, 534-540. http://dx.doi.org/10.1007/s13369014-1216-2.

29. Resolução $A N P n^{\circ}$ 32, de 21.9.2010. (2010, 22 de setembro). Diário Oficial da República Federativa do Brasil, Brasília.

30. Bahia, H. U., \& Anderson, D. A. (1995). Strategic highway research program binder rheological parameters: background and comparison with conventional properties. Transportation Research Record, 1488, 32-39.

31. Kaci, M., Kaid, N., \& Boukerrou, A. (2011). Influence of ethylene-butyl acrylate-glycidyl methacrylate terpolymer on compatibility of ethylene vinyl acetate copolymer/olive husk flour composites. Composite Interfaces, 18(4), 295-307. http:// dx.doi.org/10.1163/092764411X584487.

32. Jun, L., Yuxia, Z., Yuzhen, Z. (2008). The research of GMAg-LDPE modified Qinhuangdao bitumen. Construction and Building Materials, 22, 1067-1073. http://dx.doi.org/10.1016/j. conbuildmat.2007.03.007.

Received: Dec. 23, 2015

Revised: May 31, 2016

Accepted: June 21, 2016 